\title{
A new method for studying platelets, based upon the low-angle light scattering technique. 2. Application of the method in experimental toxicology and clinical pathology
}

\author{
Igor V. Mindukshev ${ }^{\mathrm{a}}$, Elena E. Ermolaeva ${ }^{\mathrm{b}}$, Elena V. Vivulanets ${ }^{\mathrm{c}}$, Elena Yu. Shabanova ${ }^{\mathrm{c}}$, \\ Nikolay N. Petrishchev ${ }^{\mathrm{c}}$, Nikolay V. Goncharov ${ }^{\mathrm{b}}$, Richard O. Jenkins ${ }^{\mathrm{d}, *}$ and \\ Alexander I. Krivchenko ${ }^{a}$ \\ ${ }^{a}$ I.M. Sechenov Institute of Evolutionary Physiology and Biochemistry, Russian Academy of Sciences, \\ St-Petersburg, Russia \\ ${ }^{\mathrm{b}}$ Research Institute of Hygiene, Occupational Pathology and Human Ecology, St-Petersburg, Russia \\ ${ }^{\mathrm{c}}$ I.P. Pavlov Medical University, St-Petersburg, Russia \\ ${ }^{\mathrm{d}}$ School of Allied Health Sciences, De Montfort University, Leicester, UK
}

\begin{abstract}
A new method for studying platelets based on low-angle light scattering has been applied to studies in experimental toxicology and clinical pathology, using animal and human platelets. Index $\mathrm{EC}_{50}$ for ADP within control groups was estimated to be in the range of $100-180 \mathrm{nmol}^{-1}$ (healthy men, rabbits, rats). The refractory state of platelets was obtained by use ADP or ATP concentrations that just caused platelet activation. The time constant and the half-cycle of the refractory state of platelets were calculated. Kinetic parameters of platelet aggregation at interference of hemostasis (rabbit) and the influence of the age factors on the aggregation indices of platelets (rat) were studied. The method of low-angle light scattering was used as a diagnostic tool in experimental low-level intoxication by organophosphates and for interpretation of the pathogenesis of delayed effects. In human patients with ischemic heart disease or with prosthetic heart valves, significant changes in the functional state of platelets were observed. A model for cooperative binding of receptors with ligands on platelets from pregnant women with preeclampsia was developed.
\end{abstract}

Keywords: Platelets, aggregation, light scattering, preeclampsia, toxicology, pathology

\section{Introduction}

The theoretical and experimental foundations of a new method for studying platelets has been described in Part 1 [1]; it was shown that alterations in light scattering signal at angles below six degrees was determined by platelet aggregation dynamics (aggregation, disaggregation, coagulation). Standardization of testing conditions made it possible to characterize the initial functional state of platelets by their sensitivity to the action of agonists, with estimation of $\mathrm{EC}_{50}$ and maximally possible velocity of aggregation $\left(U_{\max }\right)$ values. Part 1 also highlighted the advantages of the new method of low-angle light

\footnotetext{
${ }^{*}$ Corresponding author: R.O. Jenkins, School of Allied Health Sciences, De Montfort University, Leicester, LE1 9BH, UK. Tel.: +44 116 2506306; E-mail: roj@dmu.ac.uk.
} 
scattering technique in comparison with other light scattering techniques. In the present work (Part 2) we report on the application of the method to studies in experimental toxicology and clinical pathology, using animal and human platelets.

\section{Materials and methods}

\subsection{Obtaining platelet rich plasma (PRP)}

Experiments were conducted with mature male Wistar or non-pedigree rats and "chinchilla" rabbits (animals were purchased from the breeding facility "Rappolovo", Leningrad Region, Russia). All the animals were fed with standard fodder and tap water ad libitum. Blood sampling from the rats, which were preliminary narcotized with nembutal at the dose of $40 \mathrm{mg} \mathrm{kg}^{-1}$ or with urethane at the dose of $1 \mathrm{~g} \mathrm{~kg}^{-1}$, was taken from the carotid artery; from the boundary vein of ear of "chinchilla" rabbits. In addition, several groups of healthy men and patients with different pathologies were sampled by taking blood being taken from the cubital vein. Sodium citrate $(3.2 \%$;H 6.0$)$ was used as anticoagulant at a 9:1 (blood : citrate) ratio. The PRP was obtained by centrifugation of the blood for $10 \mathrm{~min}$ at $200 \mathrm{~g}$.

\subsection{The light scattering measuring device}

The intensity of the scattered light was measured with a Laser Particle Analyzer, "LaSca" (Lumex Ltd, St-Petersburg, Russia), described in Part 1. A special algorithm with original software, LaSca_32, was used to register the data and to calculate experimental parameters in Excel.

\section{Results and discussion}

\subsection{Functional activity of platelets from laboratory animals}

Index $\mathrm{EC}_{50}$ values for $\mathrm{ADP}$ were in the range of $145.9 \pm 44.5 \mathrm{nmol}^{-1}(n=14)$ for rat platelets, $144.6 \pm 53.2 \mathrm{nmoll}^{-1}(n=11)$ for rabbit platelets and $158.3 \pm 46.1 \mathrm{nmol}^{-1}(n=12)$ for human platelets. Experiments for calculating $\mathrm{EC}_{50}$ values were conducted within 2 hours of obtaining the PRP. When working with the cells for more than 2 hours, a reduction in the functional activity of platelets was observed and the initial velocity of aggregation decreased. The loss of sensitivity to ADP by the cells indicates that either desensitization of purine receptors occurred [2] or intracellular concentration of cyclic nucleotides increased, requiring additional ADP to overcome the blocking action [3]. In the absence of additional stimulus, the levels of cAMP and cGMP in the cytoplasm can increase only in response to $\left[\mathrm{Ca}^{2+}\right]_{\mathrm{i}}$ increase [4]. Use of ADP and ATP at concentrations that just cause activation allowed us to obtain a similar state. The degree of manifestation of ADP-induced aggregation depended on the period of the platelets being in the active state. Rat platelets were activated with $20 \mathrm{nmol} 1^{-1} \mathrm{ADP}$ or $100 \mathrm{nmol}^{-1}$ ATP (low concentrations of the purines close to the $\mathrm{EC}_{50}$ value at the stage of activation). Subsequently, $400 \mathrm{nmol}^{-1}$ ADP (high concentration that induces aggregation) was introduced immediately and at 2 , $4,6,8 \mathrm{~min}$ to evaluate the initial velocity of aggregation. The initial velocities of aggregation induced at 2, 4, 6, 8 min after activation, were reliably reduced in comparison with that inducted immediately after activation. Figure 1 shows changes in the velocity of aggregation of rat platelets $8 \mathrm{~min}$ after induction 

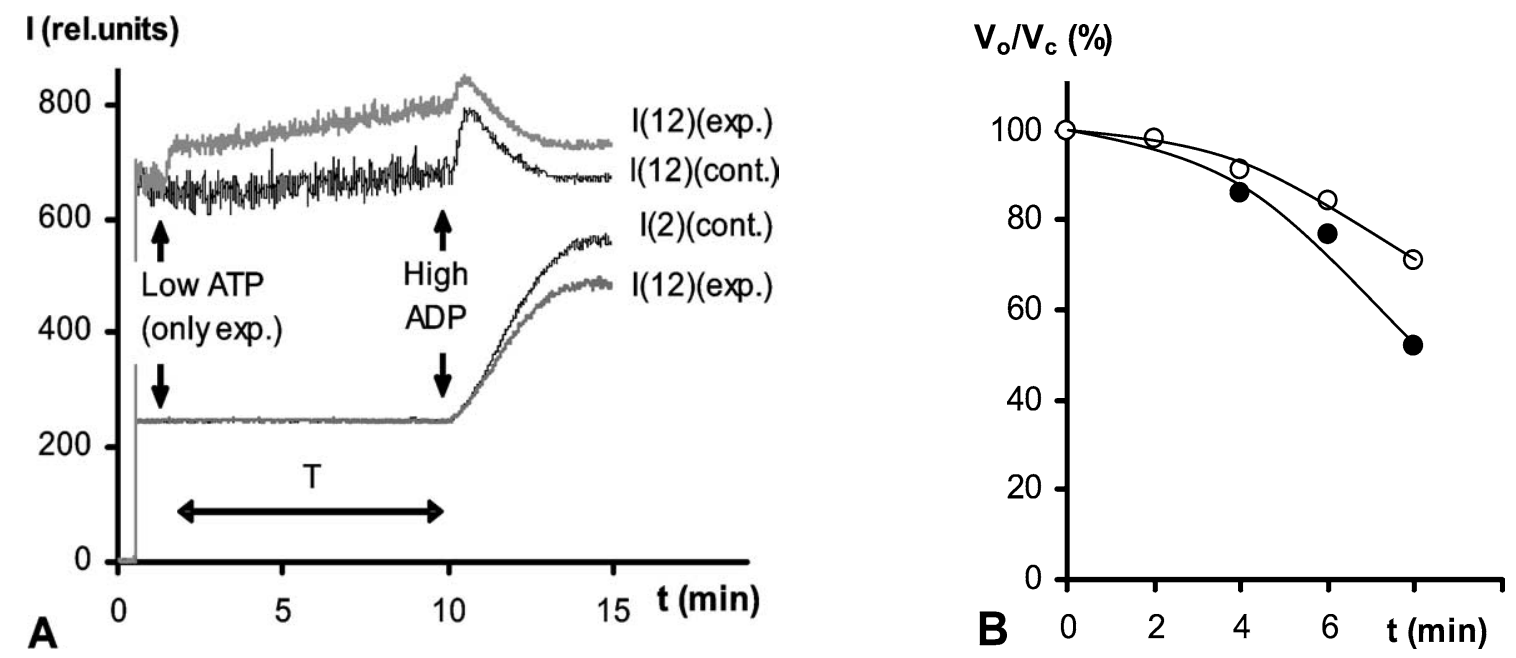

Fig. 1. (A) Changes in the velocity of aggregation of rat platelets 8 min after activation with low concentration of ATP $\left(100 \mathrm{nmol}^{-1}\right)$, in comparison with non-activated cells. (B) Dependence of initial velocity of platelet aggregation on the period of platelets being in the activated state. $\mathrm{X}$-axis is the time period for the cells in the activated state; Y-axis is the ratio of the initial velocities of aggregation (experimental group, $V_{o}$; control group, $V_{c}$ ): platelets activated by $100 \mathrm{nmol}^{-1}$ ATP $(O)$ and by $20 \mathrm{nmol}^{-1} \mathrm{ADP}(\bullet)$. The significant differences from the control are at $p \leqslant 0.05$; increase in the intensity of light scattering in the angle of 12 degrees, $\Delta I(12)$.

with low ATP concentration $\left(100 \mathrm{nmoll}^{-1}\right)$. On the contrary, the referent initial velocities of aggregation induced by high ADP concentration $\left(400 \mathrm{nmoll}^{-1}\right)$ either immediately or 8 min later did not differ between themselves (not shown here).

On the basis of the data obtained, the time constant $(k)$ and the half-cycle of the refractory state of platelets $\left(t_{1 / 2}, \min \right)$ were calculated according to the equations: $k=\ln \Delta V / \Delta T, t_{1 / 2}=\ln 2 / k$, where $\Delta V$ is the change in the initial velocity of aggregation for the time period $\Delta T$. For rat platelets, activated with $20 \mathrm{nmol}^{-1} \mathrm{ADP}, k=0.11 \pm 0.01 \mathrm{~min}^{-1}$, and $t_{1 / 2}=6.0 \pm 0.2 \mathrm{~min}(n=5)$. For platelets activated with $100 \mathrm{nmol}^{-1}$ ATP, these indices were $0.04 \pm 0.01 \mathrm{~min}^{-1}$ and $16.5 \pm 0.2 \mathrm{~min}(n=5)$, respectively.

The refractory state can also be developed under the conditions of receptor-independent increase in intracellular calcium. To achieve this, $5 \mathrm{nmol}^{-1}$ of the $\mathrm{Ca}^{2+}$-ionophore ionomycin was introduced into the cuvette with the suspended rat platelets. Incorporation of the carrier into the plasma membrane was followed by a very rapid increase in $\left[\mathrm{Ca}^{2+}\right]_{\mathrm{i}}$. The maximal amplitude of the signal at an angle of 12 degrees was $38.5 \pm 5.6 \%$. As for purine nucleotides, the degree of manifestation of the ADP-induced aggregation depended on the time period of platelets being in the activated state. The value of the time constant $k$ was $0.17 \pm 0.02 \mathrm{~min}^{-1}$, and the half-cycle of the refractory state of platelets $t_{1 / 2}$ was $4.0 \pm 0.2$ $\min (n=5)$. Thus, after platelet activation and in the absence of an additional stimulus, the cells proceed to the refractory state. The rate of development of this reaction depends on the degree of the platelet activation.

A change in the functional sensitivity of platelets to the activators of aggregation probably depends both on the initial state of intracellular signalling systems and on the development of the feedback pathways (cAMP- and cGMP-systems). Indeed, substances that induce enhancement in the level of cAMP by different mechanisms: (1) receptor-mediated activation of adenylate cyclase by adenosine through $\mathrm{A}_{2 \mathrm{~A}}$-receptor/ $\mathrm{G}_{\mathrm{s}}$-protein $\left(K_{\mathrm{i}}=405.5 \pm 10.8 \mathrm{nmoll}^{-1}, n=5\right.$, rats $)$, (2) by a direct activation of adenylate cyclase with forskolin $\left(K_{\mathrm{i}}=90.5 \pm 5.8 \mathrm{nmoll}^{-1}, n=5\right.$, rats), (3) by inhibition of 


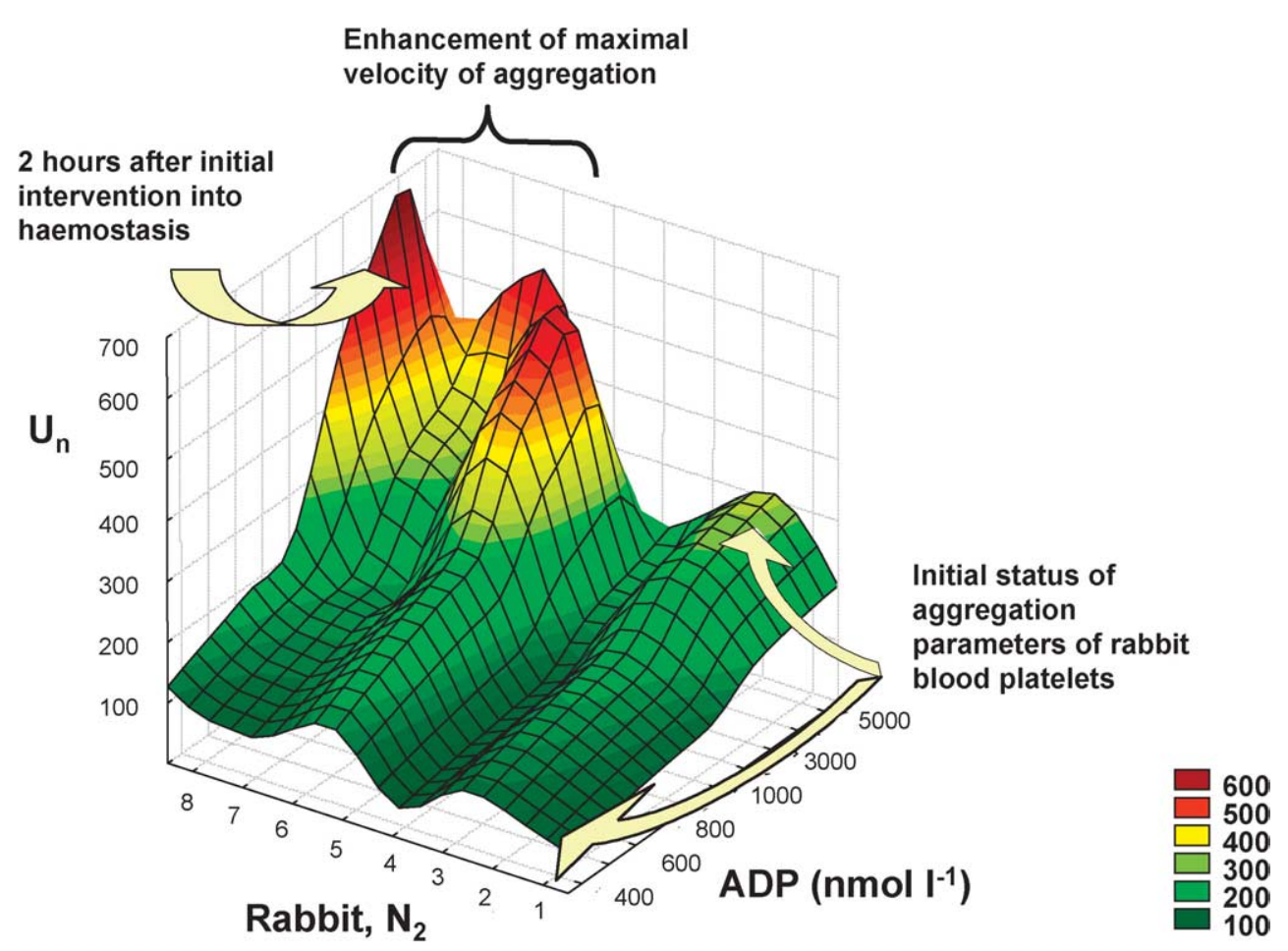

Fig. 2. Aggregation velocities of male rabbit blood platelets: initial (No. 1-4) and 2 hours after taking of blood (No. 5-8); ADP concentration range is $400-5000 \mathrm{nmoll}^{-1}$.

phosphodiesterase with no-shpa $\left(K_{\mathrm{i}}=19.7 \pm 5.3 \mu \mathrm{mol}^{-1}, n=5\right.$, rabbits $)$, (4) by a penetrating analog of cAMP - dibutyryl-cAMP $\left(K_{\mathrm{i}}=85.4 \pm 15.2 \mu \mathrm{moll}^{-1}, n=4\right.$, rats $)$. All these substances reduce the functional sensitivity of platelets, increasing $\mathrm{EC}_{50}$.

For the purpose of elaborating standard toxicological procedures and adequate evaluation of the results of an experiment we have studied the kinetic parameters of platelet aggregation at the interference to hemostasis of rabbits, as well as the influence of the age factors on the aggregation indices of rat platelets.

Evaluation of the dynamics of the platelet functional activity under the interference to hemostasis (a repeated blood sampling, 7-10 ml, after two hour interval) was carried out using 8 male rabbits of 3-4 kg body weight (Fig. 2). It was established that the blood sampling from rabbits causes an increase of the maximal velocity of aggregation $\left(U_{\max }\right)$, up to $20 \%$, with an insignificant $(<8 \%)$ decrease of $\mathrm{EC}_{50}$.

In another experiment with rats of different age (Fig. 3) a reduction in the sensitivity of platelets was shown, that could be of importance for evaluating the results, obtained in a long-term experiment (more than 6 months), and can be corrected according to the formula:

$$
V_{n}=(0.2189[\mathrm{ADP}]+847.32)-(\text { age of rats in months }-6) \times 0.005[\mathrm{ADP}]+80,
$$

where: $V_{n}$, the normalized velocity of aggregation (relative units in $\mathrm{mV}$ ); [ADP], concentration of ADP $\left(\mathrm{nmoll} 1^{-1}\right)$.

The results obtained make it possible to estimate a change in the functional state of platelets of experimental animals, and also to distinguish between the influence of a toxic factor and special functional features of the hemostasis. 


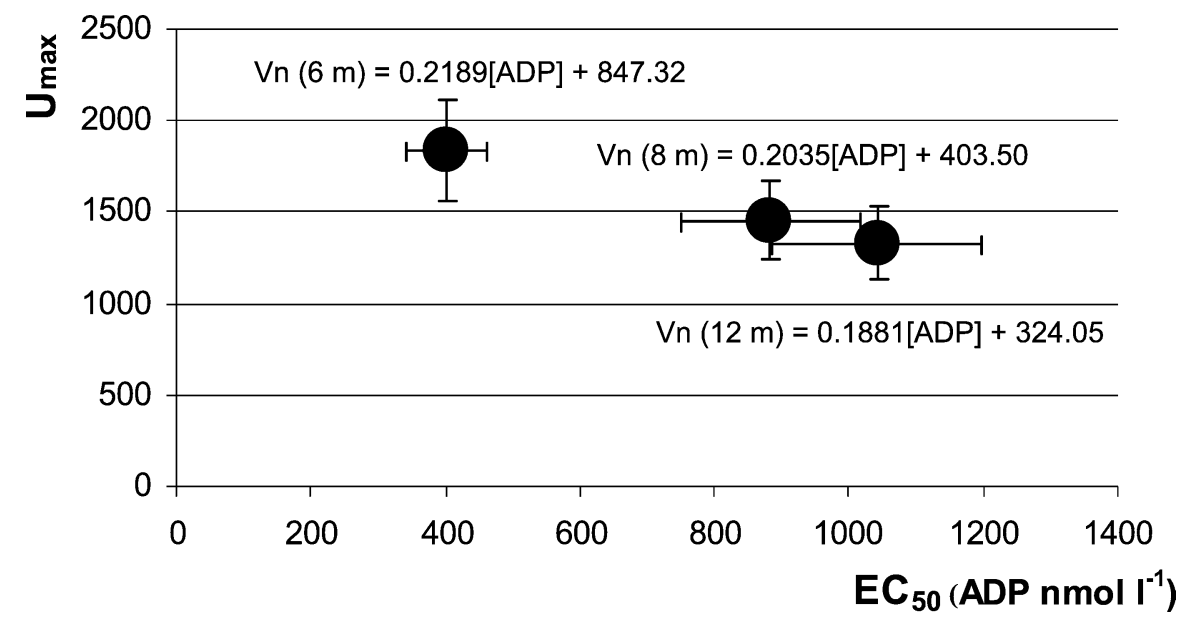

Fig. 3. Kinetic parameters of platelet aggregation for rats aged 6, 8 and 12 months.

\subsection{Investigation of the kinetic parameters of platelet aggregation in a chronic toxicological experiment}

In the case of low-level chronic intoxication by organophosphates (OP), non-cholinesterase effects are obtained that are not found with inhibition of acetyl cholinesterase (AChE, EC 3.1.1.7), butyrylcholinesterase (BChE, EC 3.1.1.8) activities and with development of cholinergic symptoms. In search for new criteria of intoxication by OP, at least two aspects of this problem - molecular and functional should be differentiated. The former concerns revealing new molecular targets of OP action, other than $\mathrm{AChE}$ and $\mathrm{BChE}$. The second (functional) aspect of this problem concerns development of pathologic symptoms, the molecular causes of which are not due to $\mathrm{AChE}$ or $\mathrm{BChE}$ inhibition. One of the first cases of OP non-cholinesterase effects (when the association between the OP molecular target and the functional disturbance has been observed) involved inhibition of kinurenin formamidase of the hen egg yolk sac membrane responsible for teratogenic effects (micromelia and abnormal feathering of the chicken). This effect is associated with reduced levels of $\mathrm{NAD}^{+}$due to blocking the conversion of tryptophane to pyridine nucleotide cofactors [5]. Another example of an OP teratogenic effect is abnormal development of the conjunctive tissue of Xenopus embryos due to inhibition of lysiloxidase and incomplete post-translational modification of collagen [6].

The blood platelet fraction, or platelet rich plasma (PRP), is a quite well understood and accessible functional model for experimental biology and medicine. However, we have not found any data of OP low dose chronic effects on the cellular component of hemostasis.

To carry out a long-term experiment, non-pedigree male rats weighing 200-220 g were used. Oethyl-S-(2-diisopropylaminoethyl)-methylthiophosphonate (Russian VX, or RVX) was dissolved daily in drinking water to concentrations of $5 \times 10^{-7}, 5 \times 10^{-6}$ and $5 \times 10^{-5} \mathrm{~g}^{-1}$. A group of 5 rats consumed $20 \mathrm{ml}$ of RVX aqueous solution daily. So, during a three month test, animals of the 1st cluster consumed RVX in drinking water to a daily dose $10^{-8} \mathrm{~g}$ (Min), animals of the 2 nd cluster $-10^{-7} \mathrm{~g}$ (Med), and those of the $3 \mathrm{rd}$ cluster $-10^{-6} \mathrm{~g}$ (Max) per $1 \mathrm{~kg}$ body weight. Changes of the animals' weights were checked, and concentrations of the solutions were appropriately corrected. Rats of the control cluster received the same drinking water without RVX. The conditions for keeping the rats, as well as their diet, were the same for all the clusters. The experimental data were obtained immediately after three months' chronic intoxication, and two and six months after stopping the chronic intoxication. 


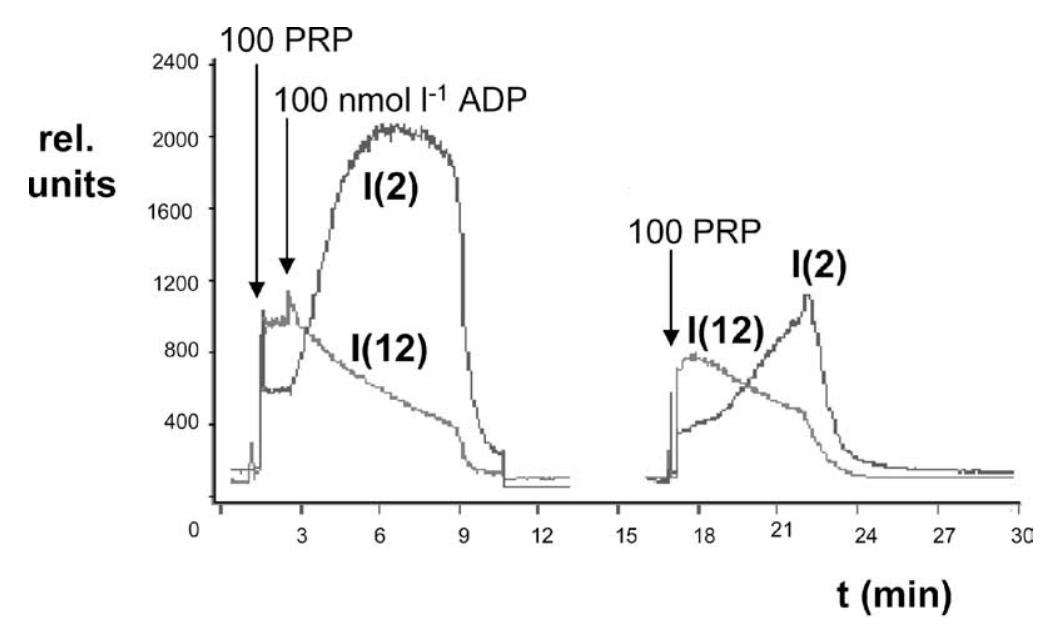

A

B

Fig. 4. (A) ADP-induced activation and aggregation of platelets of control rats. (B) Spontaneous activation and aggregation of platelets immediately after three months RVX exposure at a dose of $10^{-7} \mathrm{~g} \mathrm{~kg}^{-1}$.

Platelets of the animals exposed to RVX differ from the control by their pronounced instability, which was sometimes expressed by the development of spontaneous activation and aggregation without adding ADP into the medium (Fig. 4). In the case of ADP addition, kinetic parameters of aggregation were significantly increased with regards to both normalized maximal rate $U_{\max }$ (in all test animals) and effective concentration $\mathrm{EC}_{50}$ (in Med and Max groups, Fig. 5). Significant increase in $U_{\max }$ suggests sensitization of platelets with primary activation of signaling pathways via proteinkinase $\mathrm{C}(\mathrm{PKC})$, phosphotyrosine kinase, and phosphoinositol-3-kinase, the action of which tends to increase the expression of GPIIb/IIIa receptors [7,8]. However, non-specific RVX-phosphorylation of VASP protein by Ser-157 and Ser-239 is also possible, which could concurrently prevent the inherent phosphorylation of this protein by cAMPand cGMP-dependent kinases $[4,9]$ and to be thereby favorable for the expression of integrin receptors and aggregation of platelets.

The increase of $\mathrm{EC}_{50}$ in Med and Max groups with further $U_{\max }$ increase could be explained by a partial desensitization and/or by a decrease of the number of $\mathrm{P} 2 \mathrm{X}_{1}$ and $\mathrm{P} 2 \mathrm{Y}_{1}$ receptors, as well as by increased activity of the kinases because of development of the pathology at the microcirculatory bed. Desensitization and lack of the generalized platelet aggregation in vivo could be explained by the fact that PKC blocks the receptor-dependent increase of intracellular calcium and changes over the cell sensitivity from agonists that activate Ca-dependent reactions to agonists acting via adenylate cyclase [10]. It seems likely that compensatory mechanisms connected with the activation of platelet adenylate- and guanylatecyclases are functioning: this is mainly the synthesis of prostacyclin and nitric oxide (NO) by endothelial cells. In case of decreasing the compensatory capacity of endothelium a delayed pathology can evolve. A scaled and comprehensive chronic experiment conducted later with other OP (paraoxon and DFP) helped us to further develop the hypothesis on microangiopathies as the critical event for OP-induced delayed neuropathy and other pathological effects $[11,12]$.

\subsection{Study of the functional activity of platelets in patients with ischemic heart disease (IHD)}

Changes in the functional activity of platelets play an important role in the pathogenesis of ischemic and postischemic disorders of microcirculation. It has been shown previously that the activation of 


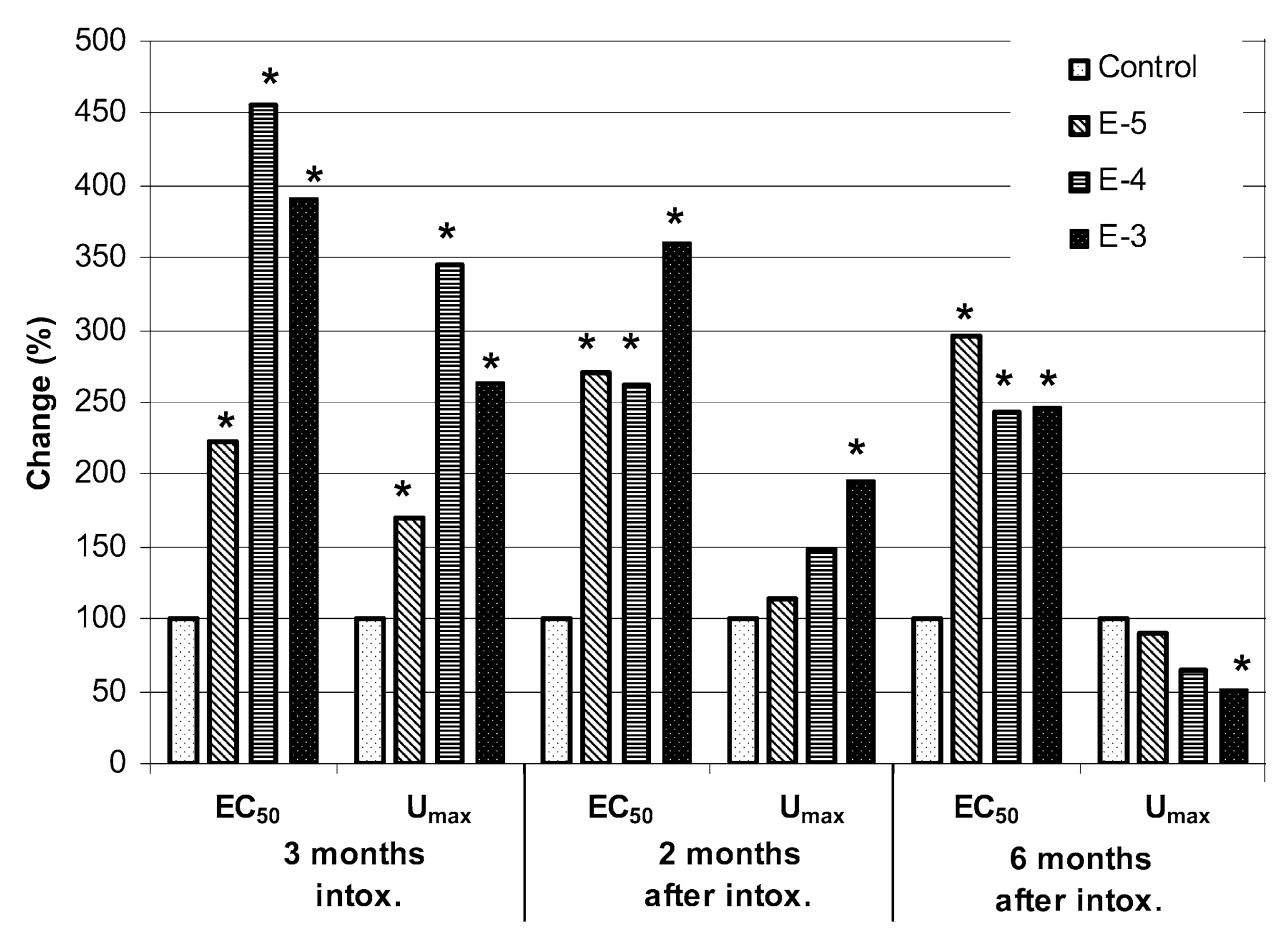

Fig. 5. Kinetic parameters of rat platelet aggregation immediately after three months RVX exposure, and at two and six months after stopping the intoxication $\left({ }^{*} p<0.05\right.$ relative to control).

fibrinogen receptors (glycoprotein complex IIb/IIIa) leads to an increase in the adhesive properties of platelets and their subsequent deposition [13]. Early reports found a correlation between the aggregative activity of platelets and IHD [14], but this was not noted in later reports [15].

A group of patients was inspected (men, $n=13$ ) having IHD (stenocardia of the functional classes I and II), which had suffered one or more myocardial infarctions before the age of 45 years (period from the last myocardial infarction was not less than 1 year). The control group composed of seven healthy men. Both for the control group and for the patients the following analyses were made: general cholesterol (GC), triglycerides (TG), and content of the lipoproteins of high (HDL), low (LDL) and very low (VLDL) densities.

The following values were obtained for the control group: platelet concentration $N=240,000 \pm$ $25,000\left(\mathrm{cells}^{-1}\right), \mathrm{EC}_{50}=160 \pm 36\left(\mathrm{nmol} \mathrm{l}^{-1}\right), U_{\max }=47.6 \pm 12.8, \mathrm{GC}=162 \pm 37\left(\mathrm{mg} \mathrm{l}^{-1}\right)$, $\mathrm{TG}=206 \pm 112, \mathrm{HDL}=46.4 \pm 7.0, \mathrm{LDL}=74.7 \pm 31.6$, and $\mathrm{VLDL}=41.3 \pm 22.5$ (all the values of lipoproteins are given in relation to cholesterol, $\mathrm{mgl}^{-1}$ ). In the group of patients average values are the following: $N=212,000 \pm 57,000\left(\right.$ cells l $\left.^{-1}\right), \mathrm{EC}_{50}=413 \pm 294\left(\mathrm{nmol} \mathrm{l}^{-1}\right)(p<0.05)$, $U_{\max }=55.4 \pm 16.0, \mathrm{GC}=227 \pm 37, \mathrm{TG}=506 \pm 362, \mathrm{HDL}=28.0 \pm 14.1, \mathrm{LDL}=109 \pm 41$ and $\mathrm{VLDL}=101 \pm 72$.

Figure 6A presents data on the dependence of the normalized initial velocity of aggregation upon ADP concentration for a healthy volunteer (control) and for a sick man with IHD. Comparing $U_{\max }$ values, it is evident that the experimental and control values are similar. Probably, a quantity of fibrinogen receptors on the surface of platelets in the patient was close to the norm. Another picture was observed with respect to the sensitivity to $\mathrm{ADP}\left(\mathrm{EC}_{50}\right)$. For the patient represented (Fig. $\left.6 \mathrm{~B}\right)$ this value increased to more 

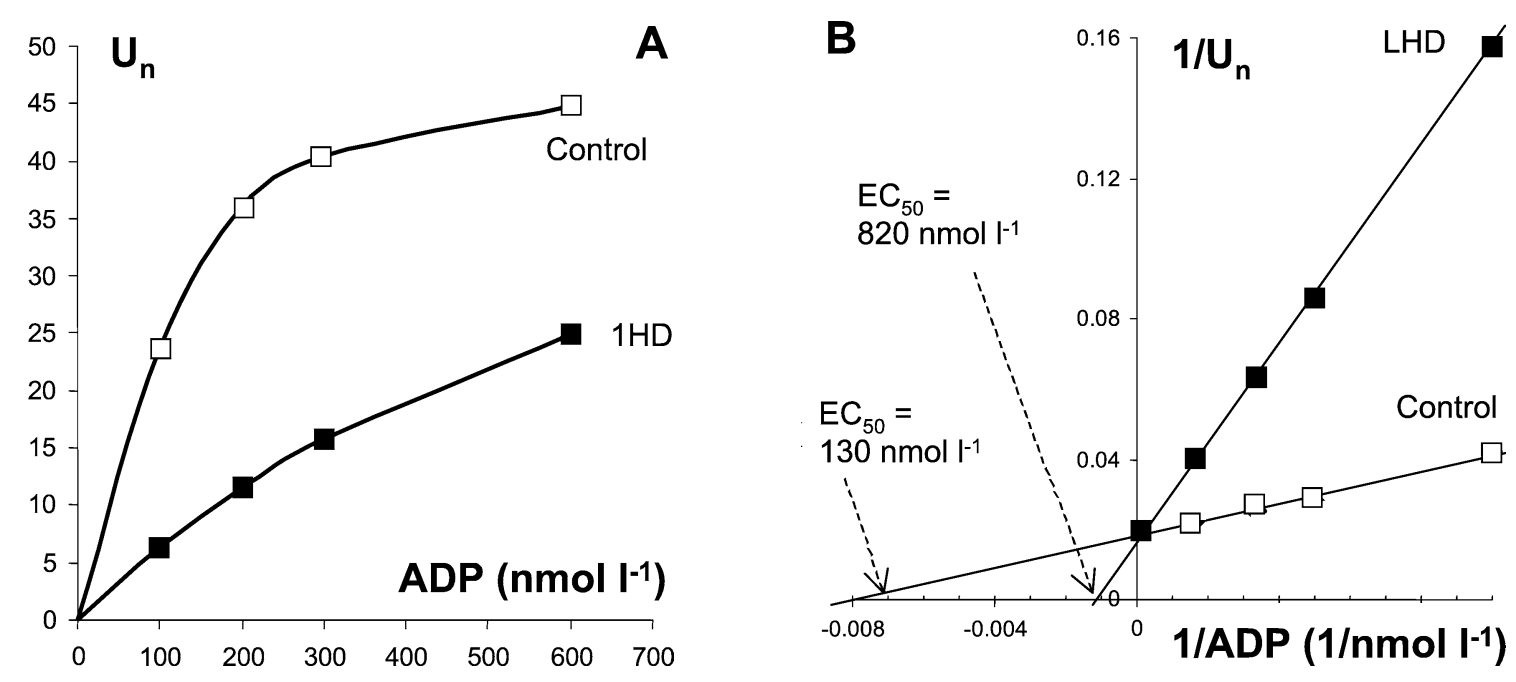

Fig. 6. (A) Dependence of the standardized initial velocity of platelet aggregation $\left(U_{n}\right)$ upon ADP concentration for healthy men (control) and for patients with IHD+hypercholesterolemia. (B) The same dependence on double reciprocal coordinates.

than six. Analysis of this index among seven patients with IHD has given the following correlation: in three patients $\mathrm{EC}_{50}$ values were close to the values of the control group (hypercholesterolemia was not observed), but in four patients the value $\mathrm{EC}_{50}$ lies within the limits of $600-1000 \mathrm{nmoll}^{-1}$. The presence of hypercholesterolemia is characteristic for this latter group. The data obtained is consistent with reduction in sensitivity of platelets to ADP in patients with IHD accompanied with hypercholesterolemia, which indicates the transition of platelets into the refractory state as a result of their permanent activation. This may be a compensation mechanism, which appears in response to constant stimulation of platelets.

\subsection{Estimation of the kinetic parameters of platelet aggregation in patients with prosthetic heart valve}

A change in the hemodynamic parameters, as well as an increase in the shift stress, in patients with artificial heart valve can give rise to thrombotic occlusion. The state of platelets, their readiness for interaction with each other and with the vascular wall has great significance in the mechanism of thrombotic complications after prosthetic heart valve surgery.

Twelve patients were investigated after prosthetics heart valves surgery (periods after operation $>1.5$ years, prosthetics were single-valved, aortal or mitral, the average age of patients was $35.9 \pm 8.7$ years). All the patients were administered oral anticoagulants for the preventive maintenance of tromboembolic complications, in four of them the therapy was augmented by aspirin. Values $\mathrm{EC}_{50}$ and $U_{\max }$ were used for evaluating the functional state of platelets.

Data on aggregation parameters for a healthy man (control) and for a patient with artificial heart valve are presented in Fig. 7, using dual opposite coordinates on the dependence of the normalized initial velocity upon ADP concentration. Analyzing the linear trend for the patient, it is evident that the line is displaced to the left, indicating a simultaneous decrease of $\mathrm{EC}_{50}$ and $U_{\max }$ values.

In this group of patients, average values are the following: $N=216.500 \pm 28.100$ (cells $1^{-1}$ ), $\mathrm{EC}_{50}=$ $61.83 \pm 36.06\left(\mathrm{nmoll}^{-1}\right)(p<0.05), U_{\max }=47.6 \pm 12.5 . \mathrm{EC}_{50}$ are inversely related to sensitivity of platelets to ADP. For the given data, this value was more than twice lower than for the control. It is 


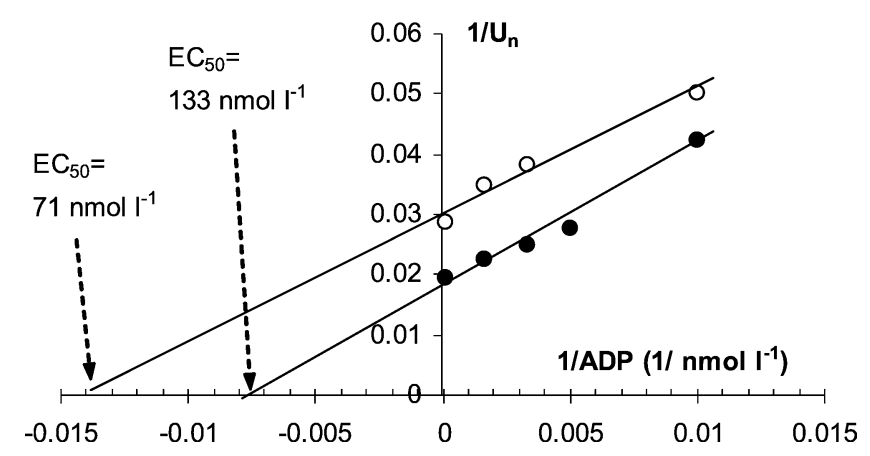

Fig. 7. Dependence of the normalized initial velocity of platelet aggregation $\left(U_{\max }\right)$ on ADP concentration for healthy donor (0) and for a patient with an artificial heart valve $(O)$.

possible that the increased sensitivity of platelets to ADP in patients with prosthetic heart valves reflects an absence (or significant suppression) of the cAMP block in the cells.

\subsection{Cooperative nature of platelet hypersensitivity for pregnant women with preeclampsia}

Platelets of 15 pregnant women with preeclampsia were investigated; the degree of gravity of this pathology was defined as nephropathy I. The blood was taken from the cubital vein. For each PRP sample between 5 to 10 independent measurements of the velocity of aggregation were made in the range of ADP concentrations of 2-40 $\mathrm{nmoll}^{-1}$. The response of the cells to very low concentrations $\left(2-5 \mathrm{nmoll}^{-1}\right)$ of agonist was observed within 30-50 minutes after obtaining PRP. Moreover, within 40-60 min coagulation of the plasma was observed.

Change in light scattering by platelets caused by aggregation under the action of very low doses of ADP is shown in Fig. 8A. On the basis of the light scattering data, the saturation curve for dependence of velocity of aggregation on ATP concentration was shown to take a sigmoidal form (Fig. 8B). For estimating the concentration of ADP at half $V_{\max }$, for a kinetic curve taking a sigmoid form, a modified Hill's equation is commonly used:

$$
V_{n}=V_{\max } \frac{[\mathrm{ADP}]^{h}}{\mathrm{EC}_{50}^{h}+[\mathrm{ADP}]^{h}}
$$

Where: $h$, Hill's coefficient; $\mathrm{EC}_{50}$, half-maximal concentration of agonist; [ADP], concentration of ADP; $V_{\max }$, maximal velocity; $V_{n}$, initial velocity.

Studying the aggregative response of platelets of the pregnant women with preeclampsia (15 patients), the following values of the platelet functional activity was obtained: $h=2.59 \pm 0.5, \mathrm{EC}_{50}=10.88 \pm 3.7$ $\left(\mathrm{nmol} 1^{-1}\right), V_{\max }=4.2 \pm 0.4$ (rel. un.). Hill's equation is assumed as the basis of a model of cooperative binding of receptor with ligand along several centers interacting between themselves. The higher the value of $n$, the more sharply the transformation from complete absence of the response of cells to their maximally possible response occurs. In our experiments, the agonist binding with the receptors occurs on more than two substrate-binding sites $(n=2.59 \pm 0.5)$. On the graph of the dependence of ADP binding with the receptors, which manifest the positive cooperative effect (Fig. 8B).

It has been shown previously [16] that activation of platelets is normally induced with the participation of the $\mathrm{P}_{2} \mathrm{X}_{1}$ receptor $\left(\mathrm{EC}_{50}\right.$ for $\mathrm{ADP}$ was found to be $\left.5-30 \mathrm{nmol}^{-1}\right)$, in which case aggregation is not observed. In our experiments the concentration range for platelet aggregation for pregnant women was 

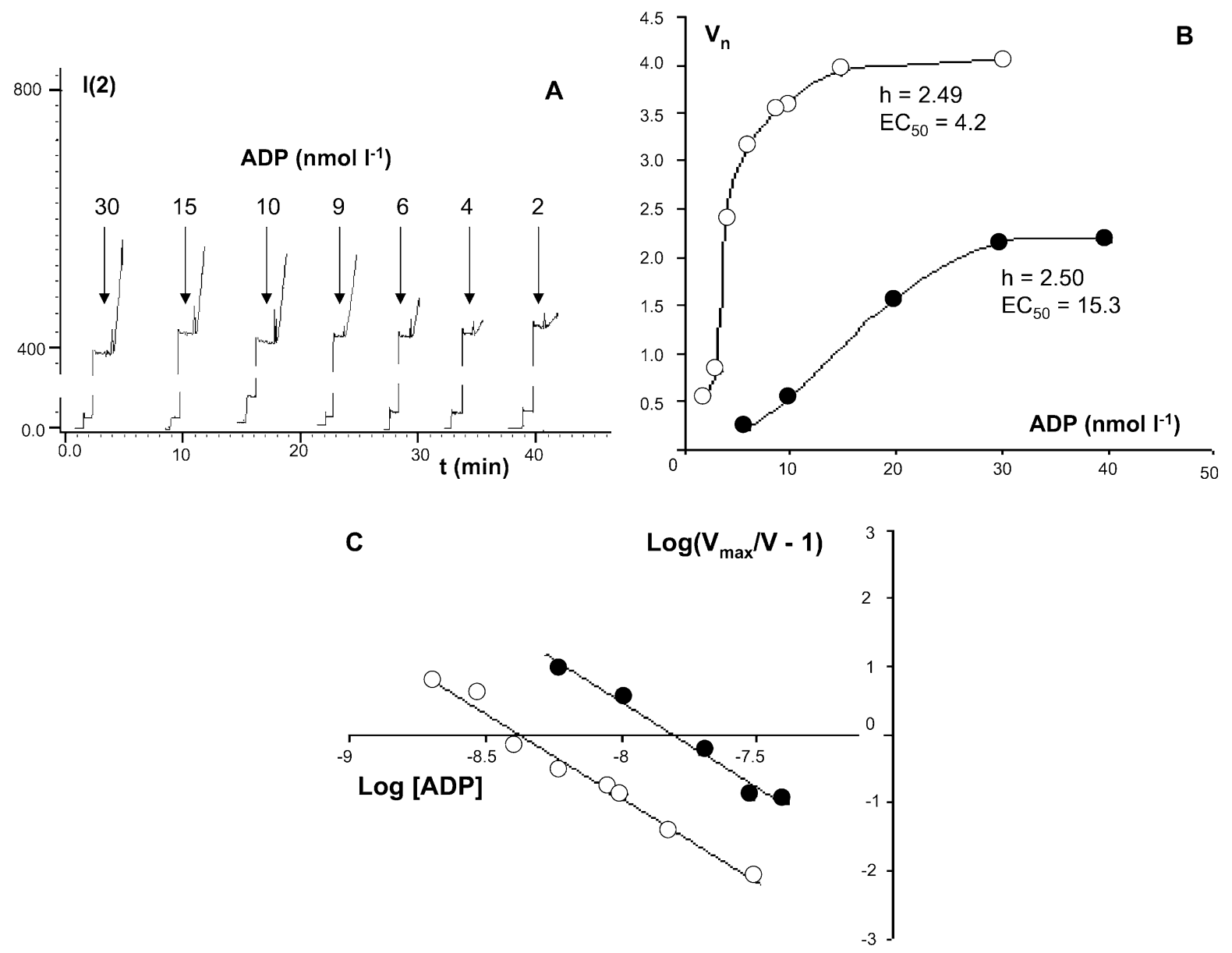

Fig. 8. (A) Changes in the light scattering by platelets under ADP action at doses $2-30 \mathrm{nmol}^{-1}$; changes of light scattering in the angle of two degrees, $I(2)$, reflect the process of aggregation; time in minutes, $t$. (B) Dependence of the maximal velocity of aggregation $\left(V_{\max }\right)$ on ADP concentration. Hill's coefficient, $h$; concentration of agonist required for half maximum velocity, $\mathrm{EC}_{50}$. The plotted points are the experimentally data obtained, while the line corresponds to the calculations with the kinetic curve. (C) Dependence of $\log \left(V_{\max } / V-1\right)$ on $\log [S]$, or the "Hill's graph".

7-15 $\mathrm{nmol}^{-1} \mathrm{ADP}$, and it is possible that aggregation of these cells is the result of cooperation of just $\mathrm{P}_{2} \mathrm{X}_{1}$ receptors. We have found no experimental evidence in the literature for cooperative opening of $\mathrm{P}_{2} \mathrm{X}_{1}$ receptors. However, the cooperative nature of desensitization of recombinant $\mathrm{P}_{2} \mathrm{X}_{1}$ receptors with nmol $1^{-1}$ concentrations of ATP has been described [2]. In our studies, we observed hypersensitivity and cooperative response of $\mathrm{P}_{2} \mathrm{X}_{1}$ platelet receptors for pregnant women at very low levels of ADP, when the desensitization of these receptors does not occur.

\section{Acknowledgement}

This work was partly supported by the BioIndustry Initiative Program of the US Department of States, ISTC grant \#2629. 


\section{References}

[1] I.V. Mindukshev, I.E. Jahatspanian, N.V. Goncharov, R.O. Jenkins and A.I. Krivchenk, A new method for studying platelets, based upon the low-angle light scattering technique. 1. Theoretical and experimental foundations of the method, Spectroscopy - Int. J. (in press).

[2] J. Rettinger and G. Schmalzing, Activation and desensitization of the recombinant P2X1 receptor at nanomolar ATP concentrations, J. Gen. Physiol. 121 (2003), 451-461.

[3] S.O. Sage, E.H. Yamoah and J.W. Heemskerk, The roles of $\mathrm{P}_{2} \mathrm{X}_{1}$ and $\mathrm{P}_{2} \mathrm{Y}_{\mathrm{AC}}$ receptors in ADP-evoked calcium signalling in human platelets, Cell Calcium 28 (2000), 119-126.

[4] U. Walter, M. Eigenthaler, J. Geiger and M. Reinhard, Role of cyclic nucleotide-dependent protein kinases and their common substrate VASP in the regulation of human platelets, in: Mechanisms of Platelet Activation and Control, Plenum Press, New York, 1993, pp. 237-249.

[5] J. Seifert and J.E. Casida, Relation of yolk sac membrane kynurenine formamidase inhibition to certain teratogenic effects of organophosphorus insecticides and of carbaryl and eserine in chicken embryos, Biochem. Pharmacol. 27 (1978), 26112615 .

[6] J.E. Snawder and J.E. Chambers, Osteolathyrogenic effects of malathion in Xenopus embryos, Toxicol. Appl. Pharmacol. 121 (1993), 210-216.

[7] J. Geiger, C. Nolte and U. Walter, Regulation of calcium mobilization and entry in human platelets by endothelium-derived factors, Amer. J. Physiol. 267 (1994), C236-C244.

[8] S.J. Shattil, H. Kashiwagi and M. Pampori, Integrin signalling: the platelet paradigm, Blood 91 (1998), 2645-2657.

[9] J. Geiger, J. Brich, P. Honig-Liedl, M. Eigenthaler, P. Schanzenbacher, J.M. Herbert and U. Walter, Specific impairment of human platelet P2Y(AC) ADP receptor-mediated signaling by the antiplatelet drug clopidogrel, Arterioscler. Thromb. Vasc. Biol. 19 (1999), 2007-2011.

[10] P.V. Avdonin and V.A. Tkachuk, [Receptors and intracellular calcium] (in Russian), Nauka, Moscow, 1994, 288 pp.

[11] N.V. Goncharov, A.S. Radilov, I.V. Mindukshev, Ye.Ye. Yermolayeva, S.V. Kuznetsov, L.M. Glashkina, I.A. Dobrylko and A.V. Kuznetsov, Effects of RVX low dose chronic exposure on rat platelet aggregation and physiology of nerve fibres, in: Economy, Logistic, and Ecology in Armed Forces III. International Scientific Conference in Brno, 2003, pp. 63-70.

[12] N. Goncharov, A. Radilov, E. Ermolaeva, L. Glashkina, I. Mindukshev, S. Kuznetsov, A. Khatkevich, P. Avdonin and A. Kuznetsov, On pathogenesis of delayed effects of RVX and other organophosphates low-dose chronic exposure, in: 8th International Symposium on Protection against Chemical and Biological Warfare Agents, Gothenburg, Sweden, Medical aspects C, 2004.

[13] F.J. Neumann, R. Blasini, C. Schmitt, E. Alt, J. Dirschinger, M. Gawaz, A. Kastrati and A. Schomig, Effect of glycoprotein $\mathrm{IIb} / \mathrm{III}$ receptor blockade on recovery of coronary flow and left ventricular function after the placement of coronary-artery stents in acute myocardial infarction, Circulation 98 (1998), 2695-2701.

[14] P.C. Elwood, S. Renaud, D.S. Sharp, A.D. Beswick, J.R. O'Brien and J.W. Yarnell, Ischemic heart disease and platelet aggregation. The Caerphilly Collaborative Heart Disease Study, Circulation 83 (1991), 38-44.

[15] T.W. Meade, J.A. Cooper and G.J. Miller, Platelet counts and aggregation measures in the incidence of ischaemic heart disease (IHD), Thromb. Haemost. 78 (1997), 926-929.

[16] M.R. Sakaev, I.V. Mindukshev, E.E. Lesiovskaia, N.N. Petrishchev and A.I. Krivchenko, [Efficacy of purine nucleotides on purinergic P2 platelet receptors by small angle light scattering] (in Russian), Eksp. Klin. Farmakol. 63 (2000), 65-69. 


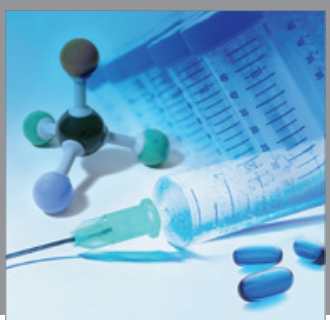

International Journal of

Medicinal Chemistry

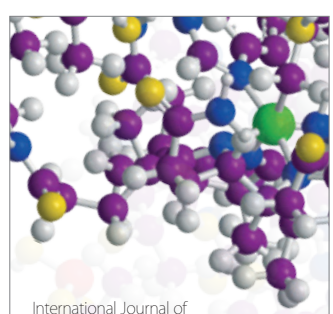

Carbohydrate Chemistry

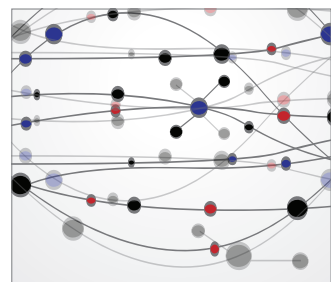

The Scientific World Journal
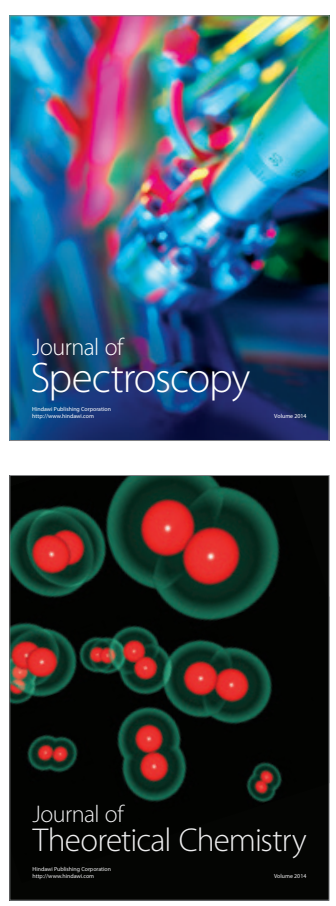
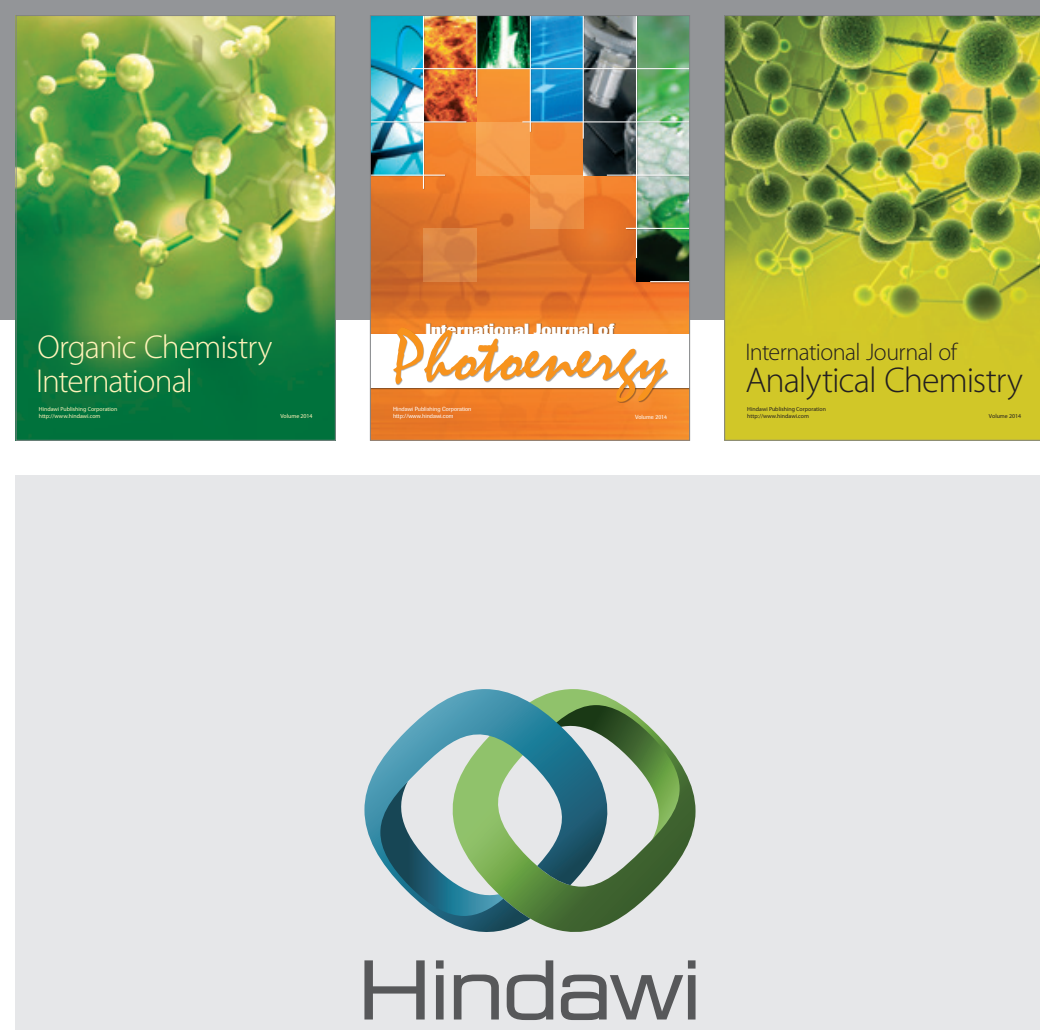

Submit your manuscripts at

http://www.hindawi.com
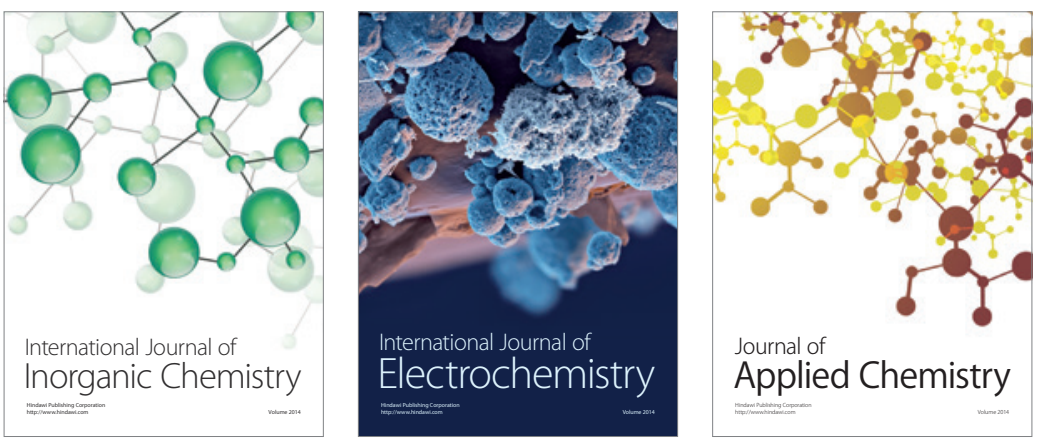

Journal of

Applied Chemistry
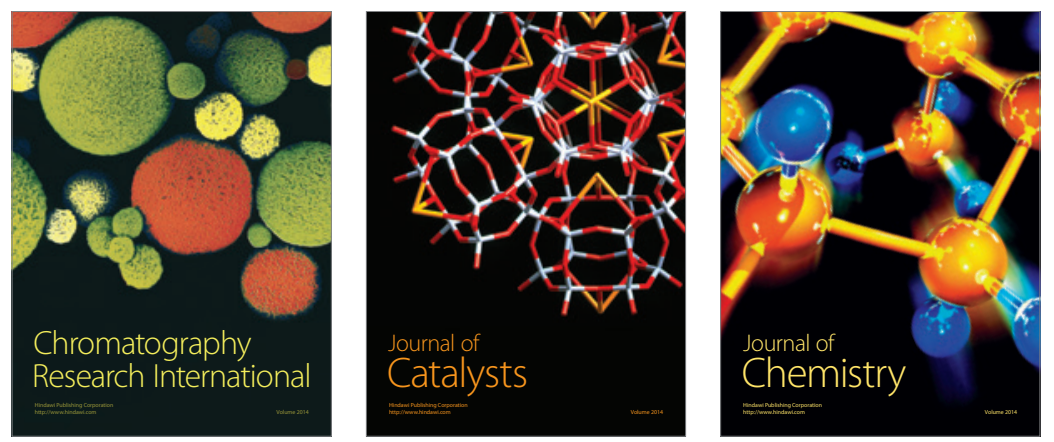
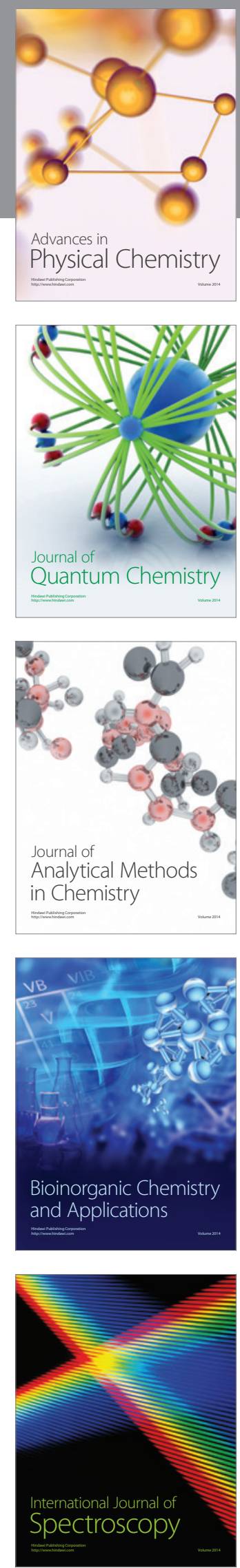